\title{
Sorption kinetics and dynamic studies of basic dye by lowcost nanoporous activated carbon derived from Ipomoea Carnea stem waste by sulphate process
}

\author{
Arockiaraj $\mathrm{I}^{\mathbf{H}^{*}}$ and Renuga $\mathrm{V}^{2}$ \\ ${ }^{1}$ Department of Chemistry, Pavendar Bharathidasan College of Engineering and Technology, Trichy, TN, India \\ ${ }^{2}$ Department of Chemistry, National College, Trichy, TN, India
}

\begin{abstract}
Nanoporous activated carbon materials were prepared from abundantly available Ipomoea Carnea stem waste. A series of Nanoporous carbon samples were prepared by subjecting the carbon material to various chemical processes. These materials accumulate superior properties and good adsorption behaviours. The adsorption capacity of selected derived carbon sample using Ipomoea Carnea stem wasteA prepared by Sodium Sulphate process was much greater than the capacities of the other carbons prepared by various processes. The adsorption of Basic Violet 10 (Basic dye) on this Sulphate treated activated carbon was investigated to assess the possible use of this adsorbent for the processing of dyeing industry wastewater. The influence of various factors such as initial dye concentration, agitation time and temperature on the adsorption capacity has been studied. The percentage removal of dye is observed to decrease with the increase in initial dye concentration. With increase in temperature, the adsorption of dye also decreases, indicating exothermic nature of the reaction. Adsorption isothermal data could be interpreted by the Langmuir and Freundlich equations. Kinetic data have been studied using Elovich, Pseudo-first order and Pseudo-second order equations for understanding the reaction mechanism.
\end{abstract}

\section{Introduction}

Activated carbon has been extensively used for the purpose of water purification. In particular, it has been commonly used for the removal of organic dyes from textile waste water. Discharge of organic pollutants like dyeing industry wastewater into water bodies contaminates the environment. Activated carbon is quite expensive and its regeneration produces additional effluent and results in considerable loss (10-15\%) of the adsorbent. Many reports have appeared on the development of lowest activated carbon adsorbents developed from cheaper and readily available materials [1]. Nanoporous carbon material with large surface area, micro porous character and chemical nature of their surface have made them potential adsorbents for removal of heavy dyes from industrial wastewater. The adsorptive properties of activated carbon for removal of pollutants are well documented [2]. Adsorption of hazardous soluble chemicals from wastewater in to surface of a solid adsorbent has provided a new dimension to wastewater technology [3]. One of the major challenges associated with adsorption by activated carbon is its cost effectiveness. This has led many workers to search for cheaper substitutes. Crab shell [4] peanut hull pellets [5], Petiolar felt-seath of palm [6], corn starch [7], soyabean hull and sugar beat fibre [8], rice husk [9], spent grain [10], de-oiled soya [11], Ipomoea carnea stem Pomegranate peel [8], and sawdust [12] are some new adsorbents, which have been tried with varying success. Moreover, the affinity of carbon surface towards solute molecules must be enhanced in order to increase the extent of solute adsorption. Comparison of size information available for commercial activated carbon pores and solute molecules in natural waters suggest that some fractions of solute will be able to access finer carbon pores [13]. In the present work, we have prepared Nanoporous activated carbon from Ipomoea carnea stem waste which is used as an adsorbent for Basic Violet 10 removal and the adsorption capacity of chosen adsorbent was regulated by many influencing factors such as temperature, $\mathrm{pH}$ variations and initial dye concentrations. The kinetic and equilibrium adsorption data obtained were correlated to characterize the prepared carbon sample for the adsorption of Basic Violet 10.

\section{Materials and methods}

\section{Adsorbent}

The study of Ipomoea carnea based carbon material is used as adsorbent which is expected to be economical, environmentally safe and it has practical importance. The raw stems of Ipomoea Carnea were collected from in and around Trichy district, TamilNadu, India. They were cut into small pieces and dried in sunlight until the moisture was evaporated. The dried materials were used for the preparation of activated carbons using physical and chemical activation methods. Ipomoea carnea stem waste material was treated with Sodium Sulphate for a period of 24 hours. Then the material was placed in the muffle furnace and carbonized at $400^{\circ} \mathrm{C}$. The dried materials were powdered and activated in a muffle furnace kept at $800^{\circ} \mathrm{C}$ for a period of 60 minutes. After activation, the carbon obtained was washed sufficiently with plenty of water, dried and sieved then to desired particle size .

Correspondence to: Arockiaraj I, Department of Chemistry, Pavendar Bharathidasan College of Engineering and Technology, Trichy, TN, India, E-mail: arockiaraj.india@gmail.com

Keywords: nanoporous activated carbon, basic violet 10, adsorption

Received: January 12, 2015; Accepted: February 22, 2016; Published: February 26, 2016 

process

The $\mathrm{N}_{2}$ adsorption-desorption isotherms of activated carbons were measured at $77 \mathrm{~K}$ using a gas sorption analyzer (NOVA 1000, Quanta Chrome corporation) in order to determine the surface areas and the total pore volumes. The surface areas were calculated using the BET equation.

\section{Adsorbate}

The textile dye, Basic Violet 10, was purchased from sigma- Aldrich (Germany) and all the chemicals used were obtained as research grade chemicals and were used without purification. A stock solution of Basic Violet 10 was prepared by dissolving $1 \mathrm{~g}$ of dye in $100 \mathrm{~mL}$ of double distilled water and used for further studies by diluting as concentrations required.

\section{Batch adsorption studies}

All reagents used were of AR grade (E-merk). Different concentrations of dye solution of Basic Violet 10 were prepared with distilled water. $50 \mathrm{ml}$ of each of this dye solution of known initial concentration $\left(\mathrm{C}_{0}\right)$ and initial $\mathrm{pH}$ was taken in a $100 \mathrm{ml}$ screw-cap conical flask with a required amount of adsorbent and was agitated at a speed of $200 \mathrm{rpm}$ in a temperature controlled thermostatic shaker bath at $30^{\circ} \mathrm{C}$ for a specified period of time. Then the solution was filtered through a $0.45 \mu \mathrm{m}$ membrane filter. The concentrations of dye in solutions were determined before and after adsorption using Elico UV-visible spectrophotometer. The amount of dye adsorbed and adsorption efficiency were calculated.

\section{Determination of basic violet 10}

Basic Violet 10 was estimated spectrophotometrically. The amount of Basic Violet 10 adsorbed in $\mathrm{mg} / \mathrm{L}$ at time, $\mathrm{t}$ was computed by using the following equation.

$$
q_{t}=\frac{c_{0-} c_{t}}{m_{s}} \times v
$$

where, $\mathrm{C}_{0}$ and $\mathrm{C}_{\mathrm{t}}$ are the Basic Violet 10 concentration in $\mathrm{mg} / \mathrm{L}$ initially and at given time $t$, respectively, $\mathrm{V}$ is the volume of the Basic Violet 10 solution in $\mathrm{ml}$ and $\mathrm{m}_{\mathrm{s}}$ is the weight of the activated nanoporous carbon.

The percentage of removed Basic Violet 10 in solution was calculated using the eqn. (2)

$$
\% \operatorname{Re} \text { moval }=\frac{c_{0-} c_{t}}{m_{s}} \times 100
$$

The initial concentration of Basic Violet 10, $\mathrm{pH}$ and temperature were investigated by varying any one parameter and keeping the other parameters constant.

\section{Adsorption dynamics}

The study of adsorption dynamics describes the solute uptake rate and evidently this rate controls the residence time of adsorbate uptake at the solid-solution interface. The kinetics of Basic Violet 10 adsorption on the activated nanoporous carbon was analyzed using pseudo first order [14] pseudo second order [15] kinetic models and Elovich equation [16]. The conformity between experimental data and the model predicted values was expressed by the correlation coefficients. A relatively high $\mathrm{R}^{2}$ value indicates that the model successfully describes the kinetics of Basic Violet 10 adsorption.

\section{The pseudo first order equation}

The pseudo first - order equation [14] is generally expressed as follows.

$$
\frac{d_{q t}}{d_{t}}=k_{1}\left(q_{e}-q_{t}\right)
$$

where, $\mathrm{q}_{\mathrm{e}}$ and $\mathrm{q}_{\mathrm{t}}$ are the adsorption capacity at equilibrium and at time $\mathrm{t}$, respectively $\left(\mathrm{mg} \mathrm{g}^{-1}\right), \mathrm{k}_{1}$ is the rate constant of pseudo first order adsorption $\left(\mathrm{lmin}^{-1}\right)$. After integration and applying boundary conditions $t=0$ to $t=t$ and $q_{t}=0$ to $q_{t}=q_{t}$, the integration form of equation (3) becomes.

$$
\log \left(q_{e}-q_{t}\right)=\frac{\log \left(q_{e}\right)-k_{1}}{2.303} \times t
$$

The value of $\log \left(\mathrm{q}_{\mathrm{e}}, \mathrm{q}_{\mathrm{t}}\right)$ were linearly correlated with $\mathrm{t}$. The plot of $\log \left(\mathrm{q}_{\mathrm{e}} \mathrm{q}_{\mathrm{t}}\right) v s \mathrm{t}$ should give a linear relationship from which $\mathrm{k}_{1}$ and $\mathrm{q}_{\mathrm{e}}$ can be determined from the slope and intercept of the plot, respectively.

\section{The pseudo second order equation}

The pseudo second order adsorption kinetic rate equation is expressed as (Ho et al. 2000)

$$
\frac{d_{q t}}{d_{t}}=k_{2}\left(q_{e}-q_{t}\right)^{2}
$$

where, $\mathrm{k}_{2}$ is the rate constant of pseudo second order adsorption (g. $\left.\mathrm{mg}^{-1} \cdot \min ^{-1}\right)$. For the boundary conditions $\mathrm{t}=0$ to $\mathrm{t}=\mathrm{t}$ and $\mathrm{q}_{\mathrm{t}}=0$ to $\mathrm{q}_{\mathrm{t}}=$ $\mathrm{q}_{\mathrm{t}}$, the integrated form of equation (5) becomes.

$$
\frac{1}{q_{e}-q_{t}}=\frac{1}{q_{e}}
$$

1Which is the integrated rate law for pseudo second $\nabla$ order reaction. Equation (6) can be rearranged to obtain equation (7), which has a linear form.

$$
\frac{t}{q_{t}}=\frac{1}{k_{2} q_{e}^{2}}+\frac{1}{q_{e}}(t)
$$

If the initial adsorption rate $\mathrm{h}\left(\mathrm{mg} \mathrm{g}^{-1} \mathrm{~min}^{-1}\right)$ is

$$
h=k_{2} q_{e}^{2}
$$

Then, Equations. (7) And (8) become:

$$
\left[\frac{t}{q_{t}}\right]=\frac{1}{h}+\frac{1}{q_{e}}(t)
$$

The plot of $\left(t / q_{t}\right)$ and $t$ of equation (7) should give a linear relationship from which $\mathrm{q}_{\mathrm{e}}$ and $\mathrm{k}_{2}$ can be determined from the slope and intercept of the plot, respectively.

\section{The Elovich equation}

The Elovich model equation is generally expressed [16] as

$$
\frac{d q_{t}}{d_{t}}=\alpha \exp \left(-\beta q_{t}\right)
$$

where, $\alpha$ is the initial adsorption rate $\left(\mathrm{mg}^{-\mathrm{g}^{-1}} \mathrm{~min}^{-1}\right), \beta$ is the adsorption constant (g. $\left.\mathrm{mg}^{-1}\right)$ during any one experiment. To simplify the Elovich equation, assumed $\alpha_{t}>t$ and by applying the boundary conditions $\mathrm{q}_{\mathrm{t}}=0$ at $\mathrm{t}=0$ and $\mathrm{q}_{\mathrm{t}}=\mathrm{q}_{\mathrm{t}}$ at $\mathrm{t}=\mathrm{t}$ Eq (10) becomes;

$$
q_{t}=1 / \beta \ln (\alpha \beta)+1 / \beta \ln t \ldots
$$



process

If Basic Violet 10 adsorption fits the Elovich model, a plot of $\mathrm{q}_{\mathrm{t}} \mathrm{vs} \ln$ $t$ should yield a linear relationship with slope of $(1 / \beta)$ and an intercept of $(1 / \beta) \ln (\alpha \beta)$.

\section{Isotherm models}

Langmuir isotherm: The study of the Langmuir isotherm is essential in assessing the adsorption efficiency of the adsorbent. This study is also useful in optimizing conditions for effective adsorption. In this respect, the Langmuir isotherm is important, though the restrictions and the limitations of this model have been well recognized [17]. below.

The Langmuir and the rearranged Langmuir equations are given

$$
\begin{aligned}
& \frac{1}{q_{e}}=\frac{1}{Q_{o} b} \cdot \frac{1}{C_{e}}+\frac{1}{Q_{o}} \\
& \frac{C_{e}}{q_{e}}=\frac{C_{e}}{Q_{o}}+\frac{1}{Q_{o} b}
\end{aligned}
$$

where,

$\mathrm{q}_{\mathrm{e}}=$ the amount of dye removed at equilibrium $(\mathrm{mg} / \mathrm{g})$

$\mathrm{C}_{\mathrm{e}}=$ the equilibrium concentration of dye $(\mathrm{mg} / \mathrm{L})$ $(\mathrm{mg} / \mathrm{g})$

$\mathrm{Q}_{0}=$ the Langmuir constant, related to the adsorption capacity

$\mathrm{b}=$ the Langmuir constant, related to the energy of adsorption $(\mathrm{L} / \mathrm{mg})$

Freundlich Isotherm: At equilibrium conditions, the adsorbed amount, $\mathrm{q}_{e}$ can also be predicted by using the Freundlich equation.

$$
q_{e}=k_{f} C_{e}^{1 / n}
$$

where,

$$
\begin{aligned}
& \mathrm{q}_{\mathrm{e}}=\text { dye concentration in solid at equilibrium }(\mathrm{mg} / \mathrm{g}) \\
& \mathrm{C}_{\mathrm{e}}=\text { dye concentration in solution at equilibrium }(\mathrm{mg} / \mathrm{L}) \\
& \mathrm{k}_{\mathrm{f}}=\text { measure of adsorption capacity } \\
& \mathrm{n}=\text { adsorption intensity }
\end{aligned}
$$

A logarithmic form of the above equation is

$$
\log q_{e}=\log k_{f}+(1 / n) \log C_{e}
$$

The values of $n$ and $k_{f}$ were determined from the plot of $\log C_{e} v$ $\log \mathrm{q}_{\mathrm{e}}$ where, $\mathrm{k}_{\mathrm{f}}$ is the indication of the adsorbent capacity and $1 / \mathrm{n}$ is a measure of surface heterogeneity, ranging between 0 and 1 , becoming more heterogeneous as its value gets closer to zero.

\section{Results and discussion}

\section{Surface characters of activated carbon}

The morphology of the surface of the prepared Nanoporous activated carbon sample was examined using Scanning Electron Micrographs. These micrographs provide positive reception of the porosity of adsorbents and consequently a qualitative evaluation of their ability to adsorb the dye molecules in solution. Ipomoea Carnea Activated Carbon (ICAC) has many pores, small cavities and rough areas with micro pores which were clearly found on the surface. This shows that dolomite treatment created welldeveloped pores with uniform distribution on the surface of the precursor, therefore leading to the activated carbon with large surface area and porous structure. The morphological study by SEM of the above adsorbent shown in the Figure 1 revealed that it is highly porous in nature [18].

\section{Characterization of adsorbent}

Physico-chemical characterizations of the adsorbent were presented in Table 1.

\section{Effect of $\mathbf{p H}$}

The $\mathrm{pH}$ value of the solution being an important controlling parameter in adsorption is mainly influenced by two factors: (i) Distribution of the dye ionized species in the solution phase and (ii) Overall charge of the adsorbent. Therefore the interaction between dye molecule and the adsorbent is basically a combined result of charges on the dye molecules and the surface of the adsorbent. The adsorption behavior of the dye on the adsorbent was studied over a wide $\mathrm{pH}$ range of $2-10$. It is observed that the $\mathrm{pH}$ significantly affects the extent of adsorption of dye over the adsorbent and a reduction in the amount adsorbed dye with increasing $\mathrm{pH}$ was observed. The maximum uptake of the Basic Violet 10 is observed at $\mathrm{pH} 8.0$ as well as a large increase in adsorption capacity was observed as the $\mathrm{pH}$ is increased above 4.2 ( pKa value of Basic Violet 10).

\section{Effect of agitation time and initial dye concentration}

The uptake of Basic Violet 10 from water by activated Ipomoea carnea stem waste carbon increased when the agitation time was varied from 10 to 250 minutes and attained equilibrium at 240 minutes and

Table 1. Characteristics of the Nanoporous Activated Carbon prepared from Ipomoea Carnea Stem Waste (ICAC).

\begin{tabular}{|l|c|}
\hline Parameter & ICAC \\
& \\
\hline Bulk density $(\mathrm{g} / \mathrm{ml})$ & 0.37 \\
Ash content $(\%)$ & 7.78 \\
$\mathrm{pH}$ & 7.76 \\
Moisture content $(\%)$ & 9.6 \\
Surface area $\left(\mathrm{m}^{2} / \mathrm{g}\right)$ & 698 \\
Iodine number(mg/g) & 655 \\
$\mathrm{pH}_{\text {zpc }}$ & 5.8 \\
porosity $(\%)$ & 59.78 \\
\hline
\end{tabular}

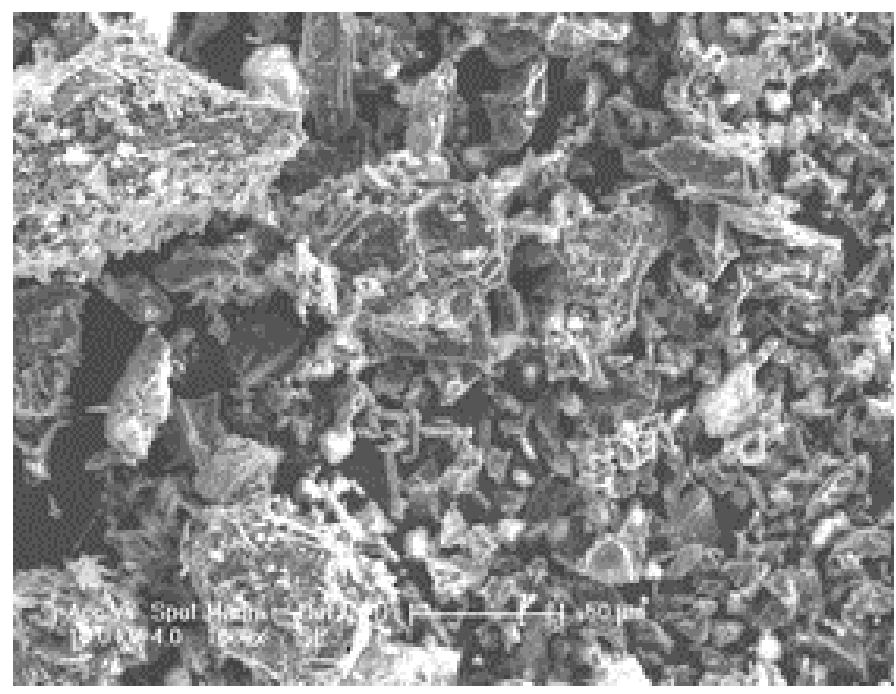

Figure 1. SEM image of ipomea carnea stem waste. 

process

when the temperature was $30^{\circ} \mathrm{C}, \mathrm{pH} 6.5$, initial concentration of the basic dye solution used was $20 \mathrm{mg} / \mathrm{L}$ and the adsorbent dosage of 50 $\mathrm{mg}$. As the initial dye concentration increases from $20 \mathrm{mg} / \mathrm{L}$ to $60 \mathrm{mg} / \mathrm{L}$, the amount of dye removal also increases. The increase in adsorption of basic dye with increase in agitation time may be attributed to the increased intra particle diffusion occurring at long shaking time (Figures 2-4). A similar result was observed by [19] in the removal of chromium using fly ash and bagasse.

\section{Effect of temperature on kinetic rate constant and rate parameters}

For this adsorption process, adsorption experiments were carried

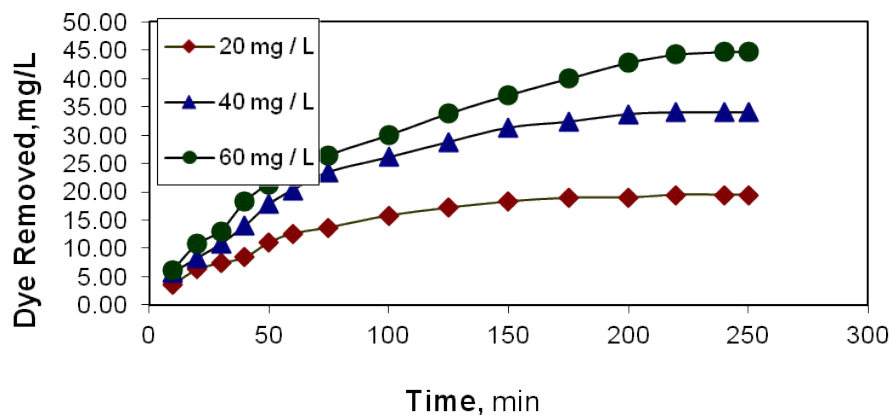

Figure 2. Effect of agitation time and initial dye concentration on basic violet 10 adsorption.

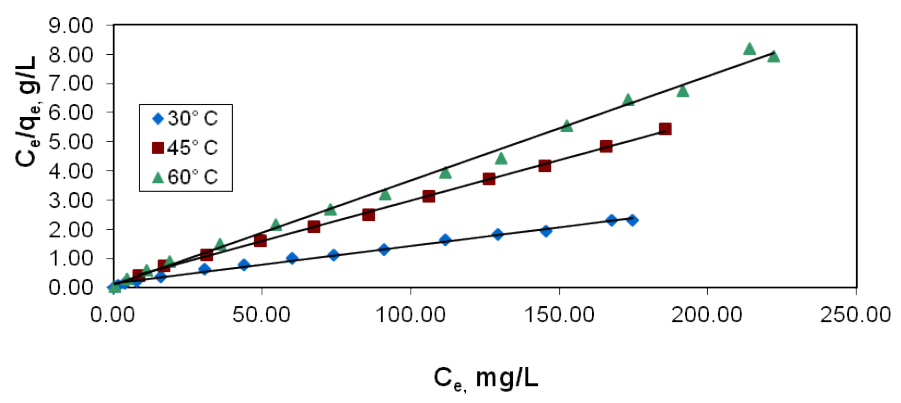

Figure 3. Effect of temperature variation on langmuir plot for basic violet10 adsorption.

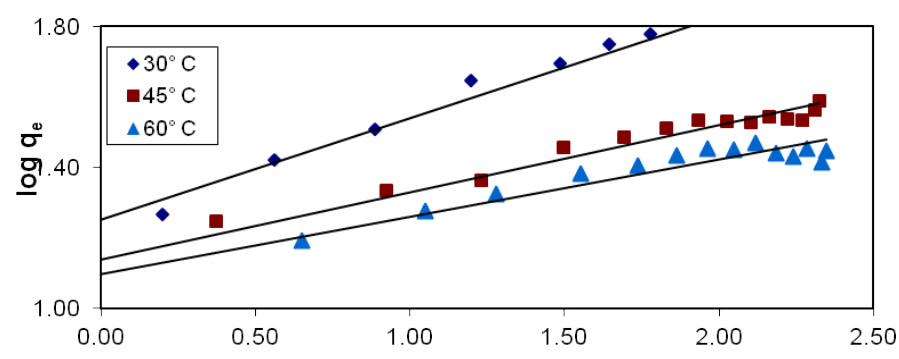

$\log C_{e}$

Figure 4. Effect of temperature variation on freundlich plot for basic violet 10 adsorption.

Table 2. The adsorption kinetic model rate constants for ICAC at different Temperatures. out with fixed initial dye concentration $(20 \mathrm{mg} / \mathrm{L})$ and $\mathrm{pH} 6.5$ at different temperatures viz. $30^{\circ} \mathrm{C} .45^{\circ} \mathrm{C}$ and $60^{\circ} \mathrm{C}$. The analysis of the data in Table 2 reveals that the influence of temperature on the dye adsorption has comparatively little effect on the pseudo first order and Elovich (Figure 5) rate constants. The Table 2 also reveals that the influence of the temperature of dye on pseudo second order (Figure 6) rate constant is appreciable. It is obvious that the adsorption of dye onto the adsorbent is best described by pseudo second order rate equation with regression coefficient value which is greater than 0.97 .

\section{Isothermal modelling}

The Langmuir adsorption isotherm Figure 3 and the values of high correlation coefficients $\left(\mathrm{R}^{2}\right)$, obtained in this study indicates the applicability of Langmuir adsorption isotherm [20]. The values of adsorption intensity reveal that the applicability of Freundlich adsorption is not good when compared to Langmuir adsorption isotherm. The values of $n, 1 / n$ and $k_{f}$ are given in Table 3 . The values of $1 / \mathrm{n}$ which lie between 0 and 1 clearly describe the surface heterogeneity. The study of temperature effects on the Freundlich parameters reveals decreasing trend in the adsorption capacity $\left(Q_{0}\right)$ with increase in temperature. These data are useful for practical design purposes [21].

\section{Conclusion}

In the present study, adsorption of Basic Violet 10 on nanoporous activated Ipomoea carnea stem waste carbon has been investigated. The data obtained through this work support that the Ipomoea carnea carbon is an effective low cost adsorbent for the removal of Basic Violet 10 from aqueous solution. The adsorption of Basic Violet 10 is dependent on the initial concentration and agitation time. Equilibrium of Basic Violet 10 adsorption reaches at 240 minutes. The values of correlation coefficients obtained in this study indicates the applicability of Langmuir adsorption isotherm. The study of temperature effects on the Freundlich parameters reveals that decreasing trend in the adsorption capacity with increase in temperature. These data are useful for practical design purposes.

The Elovich and pseudo-second order equations provided a best fit description for the sorption of Basic Violet 10 onto Ipomoea

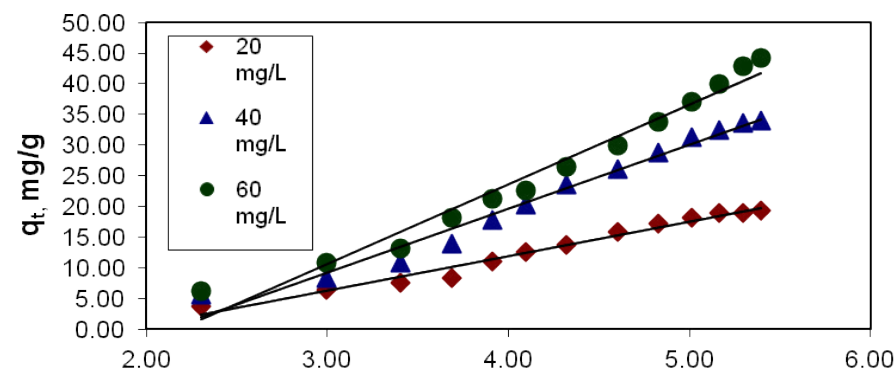

In $\mathrm{t}$

Figure 5. Effect of initial dye concentration on elovich plot for basic violet 10 adsorption.

\begin{tabular}{|c|c|c|c|c|c|c|c|c|c|}
\hline \multirow[t]{2}{*}{ Adsorbent } & \multirow[t]{2}{*}{$\begin{array}{c}\text { Initial } \\
\text { Temperature }\end{array}$} & \multicolumn{2}{|c|}{$\begin{array}{l}\text { Pseudo } \\
\text { first order }\end{array}$} & \multicolumn{3}{|c|}{$\begin{array}{c}\text { Pseudo } \\
\text { Second order }\end{array}$} & \multicolumn{3}{|c|}{$\begin{array}{c}\text { Elovich } \\
\text { Model }\end{array}$} \\
\hline & & $\begin{array}{c}k_{1} \\
\operatorname{lmin}^{-1}\end{array}$ & $\mathbf{R}^{2}$ & $\underset{\mathrm{g} \mathrm{mg}^{-1} \mathrm{~min}^{-1}}{\mathrm{k}_{2}}$ & $\begin{array}{c}\mathbf{h} \\
\mathbf{m g ~ g}^{-1} \\
\mathbf{m i n}^{-1}\end{array}$ & $\mathbf{R}^{2}$ & $\beta \operatorname{gmin}^{-1}$ & $\underset{\min ^{-1}}{\alpha}$ & $\mathbf{R}^{2}$ \\
\hline \multirow[t]{3}{*}{ ICAC } & $30^{\circ} \mathrm{C}$ & 0.0132 & 0.9279 & 2.155 & 5.729 & 0.9755 & 0.1860 & 0.478 & 0.9578 \\
\hline & $45^{\circ} \mathrm{C}$ & 0.0167 & 0.9208 & 0.0073 & 4.6662 & 0.9867 & 0.1776 & 0.566 & 0.9444 \\
\hline & $60^{\circ} \mathrm{C}$ & 0.0161 & 0.9225 & 0.0045 & 6.3860 & 0.9875 & 0.1819 & 0.467 & 0.9424 \\
\hline
\end{tabular}




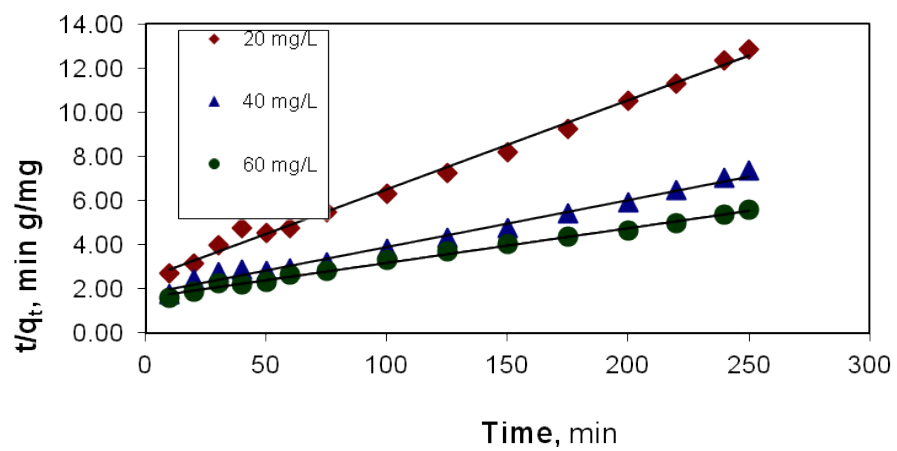

Figure 6. Effect of initial dye concentration on pseudo second order plot for basic violet 10 adsorption.

Table 3. Parameters of langmuir and freundlich adsorption isotherms for the adsorption of basic violet 10 onto ICAC.

\begin{tabular}{|c|c|r|c|c|c|}
\hline \multirow{2}{*}{ Temperature, ${ }^{\circ} \mathbf{C}$} & \multicolumn{3}{|c|}{ Langmuir Isotherm } & \multicolumn{2}{c|}{ Freundlich Isotherm } \\
\hline & $\mathbf{K}_{\mathbf{L}}$ & $\mathbf{Q}_{\mathbf{0}}$ & $\mathbf{1} / \mathbf{n}$ & $\mathbf{n}$ & $\mathbf{k}_{\mathbf{f}}$ \\
\hline $30^{\circ} \mathrm{C}$ & 9.633 & 28.12 & 0.296 & 3.353 & 17.673 \\
\hline $45^{\circ} \mathrm{C}$ & 4.927 & 36.96 & 0.191 & 5.343 & 14.677 \\
\hline $60^{\circ} \mathrm{C}$ & 7.352 & 76.45 & 0.163 & 6.253 & 12.348 \\
\hline
\end{tabular}

carnea stem waste carbon, but the pseudo-second order equation had better correlation coefficient value than Elovich equation. Therefore, pseudo-second order was considered the most appropriate due to high correlation coefficient when compared to Elovich equation and pseudo first order equation. The adsorption of Basic Violet 10 onto activated Ipomoea carnea stem waste carbon gave better results.

\section{References}

1. Babel S, Kurniawan TA (2003) Low-cost adsorbents for heavy metals uptake from contaminated water: a review. J Hazard Mater 97: 219-243. [Crossref]

2. Macias-Garcia A, Valenzuela-Calahorro C, Gomez-Serrano V, Espinosa-Mansilla A (1993) Adsorption of $\mathrm{Pb} 2+$ by heat-treated and sulfurized activated carbon. Carbon 31: $1249-1255$.

3. Benefield LD, Judkins JF, Weand BL (1982) Process Chemistry for Water and Wastewater Treatment, Prentice-Hall, Englewood Cliffs, NJ.

4. An HK, Park BY, Kim D S (2001) Crab shell for the removal of heavy metals from aqueous solution. Water Res 35: 3551-3556. [Crossref]
5. Brown P, Jefcoat IA, Parrish D, Gill S, Graham E (2000) Evaluation of the adsorptive capacity of peanut hull carbon for heavy metals in solution. Advanced Environmental Research 4: 19-29 Iqbal.

6. Iqbal M, Saeed A, Akhtar N (2002) Petiolar felt-sheath of palm: a new biosorbent for the removal of heavy metals from contaminated water. Bioresour Technol 81: 151-153. [Crossref]

7. Kweon DK, Choi JK, Kim EK, Lim ST (2001) Adsorption of divalent ions by suecinylated and oxidized cornstarch. Carbohydrate Polymers, 46: 171-177.

8. Jambulingam M, Renugadevi N, Karthikeyan S, Kiruthika J, Pattabi S (2005) Adsorption of $\mathrm{Cr}(\mathrm{VI})$ from aqueous solution using a low cost carbon. Indian Journal of Environmental Protection, 25: 458-463.

9. Low KS, Lee CK (1997) Quaternized rice husk as sorbent for reactive dyes. Bioresource Technology 61: 121-125.

10. Low KS, Lee CK, Lie SC (2000) Sorption of cadmium and lead from aqueous solution by spent grain. Process.

11. Gupta VK, Mittal A, Gajbe V (2005) Adsorption and desorption studies of a water soluble dye, Quinoline Yellow, using waste materials. J Colloid Interface Sci 284: 8998. [Crossref]

12. Marshall WE, Johns MM (1996) Agricultural by-products as metal adsorbents: Sorption properties and resistance to mechanical abrasion. Journal of Chemical Technology Biotechnology 66: 192-198.

13. Namasivayam C, Yamuna RT (1999) Studies on chromium (III) removal from aqueous solution by adsorption onto biogas residual slurry and its application to tannery wastewater treatment. Water, Air and Soil Pollution 113: 371-384.

14. Lagergren S (1898) Zur theorie der Sogenannten Adsorption geloster stoffe, Kungliga Svenska Vetenskapskademiens. Handlingar 24: 1.

15. Ho YS, Macy G (2000) Study of the Sorption of Divalent Metal Ions to Peat. Adsorpt. Sci. Technol 18: 639-650.

16. Chien SH, Clayton WR (1980) Application of Elovich equation to the Kinetics of Phosphate Release and Sorption on Soils.Soil Sci. Soc. Am. J 44: 265-268.

17. Langmuir I (1918) The adsorption of gases on plane surface of glass, mica and platinum. Journal of American Chemical Society 40: 1361-1403.

18. Yoshida H, Fukuda S, Okamota A, Kataoko T (1993) Adsorption of acid dye on cross-linked chitosan fibres. Equilibria Chemical Engineering Science 48: 2267-2272.

19. Rao M, Bhole AG (2001) Chromium removal by adsorption using fly ash and bagasse. Journal of .Indian Water Works Association 97: 997-1000.

20. Karthikeyan S, Bhuvaneswari G, Malathi S, Maheswari P, Sivakumar B (2007) Studies on removal of textile effluents using Ipomoea Carnea stem waste activated carbon. $J$. Ind. Council Chem 24: 63-67.

21. Karthikeyan S, Sivakumar P, Palanisamy PN (2008) Novel activated carbons from agricultural wastes and their characterization. Journal of Chemistry 5: 409-426.

Copyright: $(2016$ Arockiaraj I. This is an open-access article distributed under the terms of the Creative Commons Attribution License, which permits unrestricted use, distribution, and reproduction in any medium, provided the original author and source are credited. 